Article

\title{
Experimental Investigation on the Cooling and Inerting Effects of Liquid Nitrogen Injected into a Confined Space
}

\author{
Huaijun Ji ${ }^{1,2}$, Yunzhuo Li ${ }^{1}$, Hetao Su ${ }^{1,2, *}$, Wuyi Cheng ${ }^{1,2}$ and Xiang Wu ${ }^{1,2} \mathbb{D}$ \\ 1 School of Engineering and Technology, China University of Geosciences (Beijing), Beijing 100083, China; \\ jhjun2015@cugb.edu.cn (H.J.); liyunzhuo@cugb.edu.cn (Y.L.); cwy@cugb.edu.cn (W.C.); \\ wuxiang@cugb.edu.cn (X.W.) \\ 2 Key Laboratory of Deep Geodrilling Technology, Ministry of Land and Resources, China University of \\ Geosciences (Beijing), Beijing 100083, China \\ * Correspondence: h.su@cugb.edu.cn; Tel.: +86-198-0130-7501
}

Received: 15 March 2019; Accepted: 17 April 2019; Published: 22 April 2019

\begin{abstract}
As a highly effective and environmentally benign suppression agent, liquid nitrogen $\left(\mathrm{LN}_{2}\right)$ has been widely used for fire extinguishing in plants, dwellings, enclosed underground tunnels, and other confined spaces through cooling and inerting. It is of great significance to understand the cooling and inerting effects of $\mathrm{LN}_{2}$ injected into a confined space. A confined-space experimental platform was developed to study the injecting $\mathrm{LN}_{2}$ into the platform with different injection parameters, such as mass flux, pipe diameter, and inclination angle. In addition, a mathematical model of quantitatively assessing cooling and inerting effects was proposed by using heat transfer capacity, inerting coefficient, and cooling rate. Results showed that the inerting effect was gradually enhanced with a mass flux increasing from 0.014 to $0.026 \mathrm{~kg} / \mathrm{s}$ and then tended to level off; an appropriate pipe diameter of $12 \mathrm{~mm}$ was optimal for the cooling and inerting effects in this experiment. In addition, a positively increasing inclination angle could contribute to the cooling and inerting effects. However, there was little effect on the cooling and inerting with an inclination angle less than $0^{\circ}$. This study can provide technical guidances for environmentally friendly fire extinguishing with $\mathrm{LN}_{2}$ in a confined space.
\end{abstract}

Keywords: liquid nitrogen; confined space; heat transfer; cooling rate; inerting coefficient

\section{Introduction}

Liquid nitrogen $\left(\mathrm{LN}_{2}\right)$, as an excellent low-temperature cooling and inerting medium, has been widely used in the areas of food industry, machine manufacturing, medical treatment, and space technology [1-4]. It has a series of virtues, such as safety, reliability, low price, abundance, stable performance, etc. Besides, $\mathrm{LN}_{2}$ is also an environmentally benign and highly efficient extinguishing agent and applied in fire prevention and extinguishing due to the remarkable cooling and inerting effect [5-7]. The major fire extinguishing mechanisms with $\mathrm{LN}_{2}$ include: (1) refrigeration and cooling because of the very low temperature of the cryogen and the latent and sensible heat; (2) inerting of the atmosphere-the vaporization expansion times of $\mathrm{LN}_{2}$ is high in that $1 \mathrm{~L} \mathrm{LN}_{2}$ can vaporize to $647 \mathrm{~L}$ gaseous nitrogen in the standard state [8].

In previous research, it has been identified that $\mathrm{LN}_{2}$ is an effective and environmentally friendly benign suppression agent for combustible metal fires, oil pool fires, and building fires. The effectiveness of $\mathrm{LN}_{2}$ for sodium fire suppression was quantified by measuring the pool temperature and the mass of $\mathrm{LN}_{2}$ delivered, and the suppression mechanism indicated that the cooling (via $\mathrm{LN}_{2}$ vaporization) of the pool and its surroundings were below the sodium self-ignition temperature [9]. Pool fire 
experiments were conducted with ethanol, propanol, and diesel fuel [8]. It showed that $\mathrm{LN}_{2}$ had undergone a phase change as soon as it contacted a burning surface, and the gas expanded and formed a cloud spreading over and near the surface, which revealed the fire extinguishing mechanisms of surface cooling, inerting of the atmosphere, and rapid expansion followed by gravity spread. In addition, a technique for remote-controlled application of liquid nitrogen which was effective for fire extinguishing was proposed [10]. $\mathrm{LN}_{2}$ was considered as a desirable firefighter in fighting building fires for its effectiveness and the elimination of water damage resulting from conventional firefighting methods by studying the use of $\mathrm{LN}_{2}$ in the past two decades [11]. Shi and Zhou compared the extinguishment behaviors of $\mathrm{LN}_{2}$ vertical/horizontal jets for extinguishing oil pool fires in weight, thermocouples temperature, and infrared thermal image [12]. They discovered that $\mathrm{LN}_{2}$ had an excellent performance for firefighting. The horizontal jet was more effective than the vertical jet considering the required amount of $\mathrm{LN}_{2}$ and fire extinguishing time. Fires caused by spontaneous coal combustion $[13,14]$ are the main disaster in coal mines. $\mathrm{LN}_{2}$ also plays an important role in coal mine fire prevention and extinguishing [15-17]. The immediate $\mathrm{LN}_{2}$ infusion technology has been applied in coal mines [18]. The technique is efficient in absorbing heat, and displacing oxygen and combustible gases via $\mathrm{LN}_{2}$ expansion. Shi and Zhou experimented [19] by injecting $\mathrm{LN}_{2}$ into coal porous media both in the openings and in the enclosures to study the heat and mass transfer of $\mathrm{LN}_{2}$. They analyzed the mechanism of fire prevention using liquid nitrogen in the coal mine by monitoring the temperatures and oxygen concentrations in the atmosphere. Injecting $\mathrm{LN}_{2}$ into confined spaces, such as pipelines, buildings, and underground roadways, is a complicated heat and mass transfer process. The process includes phase change, thermal conductivity, convective heat transfer, gas diffusion, and so on. The heat and mass transfer of $\mathrm{LN}_{2}$ in small confined spaces such as micro-tubes, round pipes, and horizontal and vertical pipes has been investigated by many researchers [20-22]. However, less attention has been paid to large confined spaces. Furthermore, the cooling and inerting levels were assessed only according to the changes of temperature and oxygen concentration respectively at a given measurement point. The heat and mass transfer, as well as cooling and inerting effects of liquid nitrogen on the whole space, are not further quantitatively analyzed.

Injecting $\mathrm{LN}_{2}$ into the confined space involves the transformation of gas and liquid, gas-liquid two-phase flow, and latent heat transfer of vaporization. Using a computational fluid dynamics (CFD) modeling is difficult for simulating the process. An experimental approach is appropriate, based on which the process can be conducted intuitively, and the actual features of injecting $\mathrm{LN}_{2}$ in situ can be shown well. In this paper, a multi-dimensional (temperature, relative humidity, and oxygen concentration) and multi-measurement-point confined-space experimental platform is built. The $\mathrm{LN}_{2}$ is injected into the specific confined space with different injection conditions. The spatial distributions of the temperature and oxygen concentration in the space are obtained to reveal the heat and mass transfer characteristics of $\mathrm{LN}_{2}$. The mathematical model of assessing cooling and inerting effects of $\mathrm{LN}_{2}$ in a confined space is developed to analyze the effects of mass flux, pipe diameter, and inclination angle. Based on these experiments on ameliorating injection technology, the study will contribute to improving the availability and efficiency of $\mathrm{LN}_{2}$ application for fire prevention and extinguishing.

\section{Materials and Methods}

\subsection{Experimental Setup}

Figure 1 depicts a sketch diagram of the experimental setup. The equipment consists of a confined space, an $\mathrm{LN}_{2}$ injection system, and a data acquisition system. The experimental confined space was a cuboid steel framework ( $3 \mathrm{~m}$ in length, $2 \mathrm{~m}$ in width, and $2 \mathrm{~m}$ in height) packaged with plastic films. The symphyses between the films were conglutinated with scotch tape to ensure certain air tightness. The $\mathrm{LN}_{2}$ injection system consisted of an $\mathrm{LN}_{2}$ self-pressurization buffer tank with an effective working pressure more than $0.1 \mathrm{MPa}$, a mass flowmeter with a scale flow of $0-3000 \mathrm{~kg} / \mathrm{h}$, and an accuracy level of $\pm 0.1 \%$ full scale (FS), and a low-temperature resistance steel pipe. The data acquisition system 
consisted of twenty-seven T-type thermocouples, twenty-seven OMEGA OM-62 relative humidity (RH) data loggers (a measurement range $10-90 \% \mathrm{RH}$ and a resolution of $0.01 \% \mathrm{RH}$ ), twenty-seven $4 \mathrm{OXV}$ oxygen concentration sensors (a measurement range of $0-25 \mathrm{vol} \%$, an offset less than $0.6 \mathrm{vol} \%$, and data acquisition frequency of $0.5 \mathrm{~Hz}$ ), two OMB-DAQ-2416 Series data acquisition modules with 16 channels and TracerDAQ software supplied, twenty-seven oxygen concentration transmitters, four controllers, and a computer. Twenty-seven measurement points were regularly arranged in the confined space, each equipped with a T-type thermocouple, a relative humidity data logger, and an oxygen concentration sensor. The temperature, relative humidity, and oxygen concentration at each measurement point could be monitored, stored, and displayed on the computer in real-time via the data acquisition system. Figure 1 also shows that a three-dimensional coordinate system is established with Point ' $O$ ' as the coordinate origin. The coordinate point of the $\mathrm{LN}_{2}$ injection port was set to $(3.0,1.0,0.8)$.

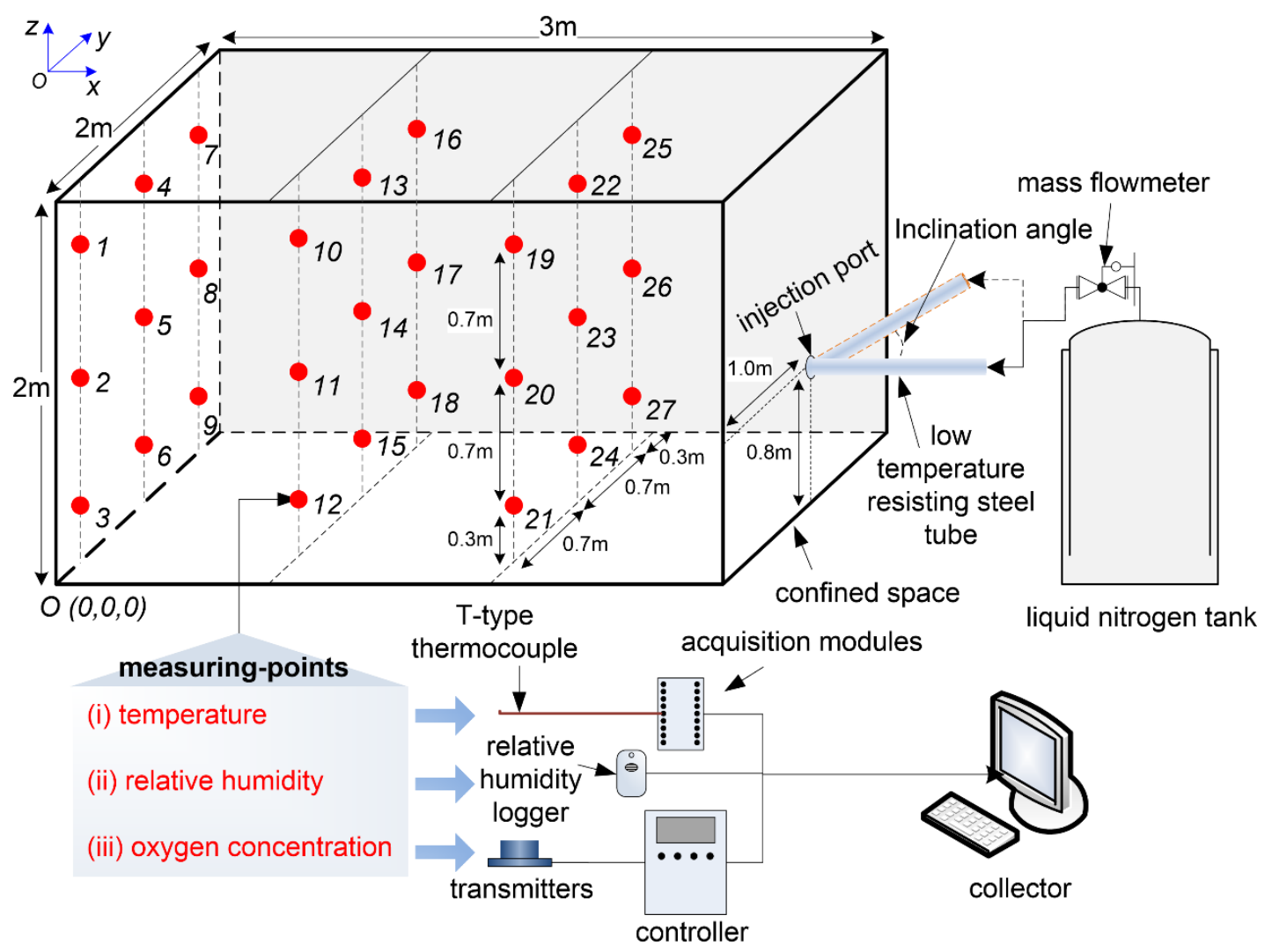

Figure 1. Sketch view of the experimental setup.

\subsection{Experimental Method}

In the experimental process, $\mathrm{LN}_{2}$ was injected from the $\mathrm{LN}_{2}$ self-pressurization buffer tank to the confined space via the low-temperature resistance steel pipe with different mass fluxes $\left(f_{\mathrm{m}}\right)$, pipe diameters $(\Phi)$, and inclination angles $\left(a_{\text {in }}\right)$. The mass flux was defined as the mass of $\mathrm{LN}_{2}$ injected into the confined space per unit of time. The inclination angle was a crossing angle between the low-temperature resistance steel pipe and horizontal plane, which represented the injection direction of $\mathrm{LN}_{2}$. The detailed parameter settings are shown in Table 1. The cooling and inerting phenomenon of $\mathrm{LN}_{2}$ in the confined space was observed with an injection duration of $180 \mathrm{~s}$. The effect of a single parameter on the temperature and oxygen concentration at each measurement point was analyzed under the conditions of maintaining other parameters unchanged. For the parameter setting of each given experiment, the data values at twenty-seven measurement points would be obtained through 
the data acquisition system. Thus, the variations in temperatures and oxygen concentrations could be analyzed.

Table 1. Detailed parameter settings.

\begin{tabular}{|c|c|c|c|c|c|c|c|}
\hline \multirow{2}{*}{ (1) } & Fixed Parameters & \multicolumn{6}{|c|}{$\Phi=28 \mathrm{~mm}, a_{\mathrm{in}}=0^{\circ}$} \\
\hline & Mass flux $f_{\mathrm{m}}(\mathrm{kg} / \mathrm{s})$ & & & 0.014 & 0.019 & 0.026 & 0.036 \\
\hline \multirow{2}{*}{$(2)$} & Fixed Parameters & \multicolumn{6}{|c|}{$f_{\mathrm{m}}=0.014 \mathrm{~kg} / \mathrm{s}, a_{\mathrm{in}}=0^{\circ}$} \\
\hline & Pipe diameter $\Phi(\mathrm{mm})$ & 4 & 12 & 20 & 28 & 32 & 40 \\
\hline \multirow{2}{*}{ (3) } & Fixed Parameters & \multicolumn{6}{|c|}{$f_{\mathrm{m}}=0.014 \mathrm{~kg} / \mathrm{s}, \Phi=20 \mathrm{~mm}$} \\
\hline & Inclination angle $a_{\text {in }}\left(^{\circ}\right)$ & & & & & & \\
\hline
\end{tabular}

\subsection{Modeling}

According to the Kamerlingh Onnes equation of state, the state equation of the mixed gases in the confined space can be expressed as:

$$
P=A \cdot \frac{\rho}{\mu}+B \cdot\left(\frac{\rho}{\mu}\right)^{2}+C \cdot\left(\frac{\rho}{\mu}\right)^{3}+\cdots
$$

where $P, \mu$, and $\rho$ are the pressure, molar mass, and density of the gas, respectively, and $A, B$, and $C$ are the virial coefficients, all being functions of temperature ( $T$ ). Equation (1) shows a probable inverse proportional relationship between $T$ and $\rho$ to some extent, when $P$ is constant.

When $\mathrm{LN}_{2}$ is injected into the confined space, it absorbs the heat inside the confined space and cools the heat medium (mixed gas) in the confined space by heat transfer. At the same time, the $\mathrm{LN}_{2}$ vaporizes to a lot of gaseous nitrogen, decreasing the oxygen concentration and inerting the confined atmosphere. The above shows that the heat transfer capacity of the heat medium and the changes in oxygen concentration can represent the cooling effect and the inerting effect of $\mathrm{LN}_{2}$ to some extent, respectively. In order to calculate the heat transfer capacity of the heat medium, it is assumed that the mixed gas in confined space consists of oxygen and nitrogen. The measurement heat medium is divided into $I \times J \times K$ micro units. A particular micro unit is regarded as the least unit for calculation. The heat transfer capacity of the heat medium in the whole confined space $(Q)$ can be calculated by Equation (2).

$$
Q=\sum_{i=1}^{I} \sum_{j=1}^{J} \sum_{k=1}^{K} Q_{i, j, k}
$$

where $i, j$, and $k$ reflect the spatial orientation of the micro unit, and $Q_{i, j, k}$ is the heat transfer capacity of the specific micro unit with the temperature ranging from $T_{1}$ to $T_{2}$, which can be expressed as Equation (3) according to the heat release from the heat medium to the $\mathrm{LN}_{2}$.

$$
Q_{i, j, k}=\frac{{ }^{c_{T_{1}, i, j, k}}+c_{T_{2}, i, j, k}}{2} \cdot \frac{\rho_{T_{1}, i, j, k}+\rho_{T_{2, i}, i, k}}{2} \cdot \Delta V \cdot\left(T_{1}-T_{2}\right)
$$

where $\rho_{T, i, j, k}$ is the dry gas density of the specific micro unit at $T$, which can be expressed as Equation (4) according to Equation (1), and $c_{T, i, j, k}$ is the specific heat of the mixed gas at $T$, and can be obtained by Equation (5).

$$
\rho_{T, i, j, k}=\frac{T_{0} \cdot\left(C_{T, i, j, k} \cdot \rho_{\mathrm{O} 2}+\left(1-C_{T, i, j, k}\right) \cdot \rho_{\mathrm{N} 2}\right)}{T}
$$

where $T_{0}$ is the temperature in the standard state $\left(T_{0}=273.15 \mathrm{~K}\right), \rho_{\mathrm{O} 2}$ and $\rho_{\mathrm{N} 2}$ are the density of oxygen, $1.429 \mathrm{~kg} / \mathrm{m}^{3}$, and the density of nitrogen, $1.251 \mathrm{~kg} / \mathrm{m}^{3}$, in the standard state, respectively, and $C_{T, i, j, k}$ is the oxygen volume fraction in the specific micro unit at $T$.

$$
\mathcal{c}_{T, i, j, k}=c_{\mathrm{a}}+c_{\mathrm{v}} \cdot H_{T, i, j, k}
$$


where $c_{\mathrm{a}}$ and $c_{\mathrm{v}}$ are the specific heat of dry air and the specific heat of water vapor, respectively. They are approximately $1.01 \mathrm{~kJ} /(\mathrm{kg} \cdot \mathrm{K})$ and $1.88 \mathrm{~kJ} /(\mathrm{kg} \cdot \mathrm{K})$ in a certain temperature range, and the water vapor in the mixed gas considered during the experiment, $H_{T, i, j, k}$ is the mass of water vapor per $\mathrm{kg}$ dry-mixed gas at $T$, which can be obtained by Equation (6).

$$
H_{T, i, j, k}=d_{T} \cdot r_{T, i, j, k}
$$

where $d_{T}$ is the water content per kg dry-mixed gas in wet-saturated mixed gas at $T, \mathrm{~g} / \mathrm{kg}$ and $r_{T, i, j, k}$ is the relative humidity of the specific micro unit, $\%$.

Furthermore, in order to analyze the inerting effect, the average oxygen concentration in the confined space $(\bar{C})$ is defined as:

$$
\bar{C}=\frac{\sum_{i=1}^{I} \sum_{j=1}^{J} \sum_{k=1}^{K} C_{i, j, k}}{I \cdot J \cdot K} .
$$

In addition, the standard deviation of oxygen concentration $(S)$ is also defined as:

$$
S=\sqrt{\frac{\sum_{i=1}^{I} \sum_{j=1}^{J} \sum_{k=1}^{K} C_{i, j, k}{ }^{2}}{I \cdot J \cdot K}-\bar{C}^{2}}
$$

and the variation coefficient $\left(C_{\mathrm{V}}\right)$ is expressed as:

$$
C_{\mathrm{V}}(\%)=\frac{S}{\bar{C}} \times 100
$$

where $C_{\mathrm{V}}$ is dimensionless. The smaller $C_{\mathrm{V}}$, the better the mixed degree is. The inerting effect can be quantified by synthesizing the decline and mixed degree of oxygen concentrations. In order to quantify the inerting degree of $\mathrm{LN}_{2}$ injected into the confined space, an inerting coefficient value $(F)$ is defined as Equation (10) to determine the inerting effect based on the drop extant of oxygen concentration and the mixed degree of nitrogen in the confined space. The smaller $F$, the better the inerting effect in confined space is.

$$
F=\frac{\bar{C}}{C_{\mathrm{O}_{2}}^{0}-\overline{\mathrm{C}}} \cdot C_{\mathrm{V}}
$$

where $\mathrm{C}_{\mathrm{O} 2}^{0}$ is the oxygen volume fraction of the atmosphere in the standard state $(21 \%)$.

\section{Results and Discussion}

\subsection{Temperatures and Oxygen Concentrations Versus Time}

An experiment of $f_{\mathrm{m}}=0.019 \mathrm{~kg} / \mathrm{s}, \Phi=28 \mathrm{~mm}$, and $a_{\mathrm{in}}=0^{\circ}$ taken as an example, a three-dimensional cubic interpolation for the temperatures and oxygen concentrations from twenty-seven measurement points was conducted. Thus, the three-dimensional distributions of temperature and oxygen concentration in the confined space at $0,90,180,360,720$, and $1440 \mathrm{~s}$ could be obtained. Figure 2 shows the values on six slices of $x=0.0,1.0,2.0 \mathrm{~m}, y=1.0 \mathrm{~m}, z=0.3,1.0 \mathrm{~m}$.

$\mathrm{LN}_{2}$ flowing through the low-temperature resistance steel pipe gradually reduced the inner-wall surface temperature of the steel pipe, resulting in the decreasing $\mathrm{LN}_{2}$ evaporation and the decreasing gas-liquid ratio of nitrogen. Figure $2 \mathrm{a}$ shows the temperature distribution. There was a spray distribution on the horizontal plane of $z=0.3 \mathrm{~m}$ and $0<x<2 \mathrm{~m}$ with the temperatures below $0{ }^{\circ} \mathrm{C}$ at $90 \mathrm{~s}$. The low-temperature area mainly occurred in $z<1.0 \mathrm{~m}$ at $180 \mathrm{~s}$ when $\mathrm{LN}_{2}$ injection was stopped. The temperatures returned to the initial state at $1440 \mathrm{~s}$, while the temperatures in $z>1.0 \mathrm{~m}$ had a little change from 0 to $1440 \mathrm{~s}$. The $\mathrm{LN}_{2}$ vaporization formed cloud spreading owing to gravity, inerted the 
atmosphere and settled $[8,19]$, so a low-temperature area concentrated at the lower place, showing the cooling effect was certain and local. Figure $2 b$ shows the oxygen concentration distribution. The oxygen concentrations in the lower space decreased firstly, while the oxygen concentrations on a horizontal plane were basically the same. At $180 \mathrm{~s}$, the oxygen concentrations in $z<1.0 \mathrm{~m}$ decreased dramatically and mostly less than $14 \%$. Because of the gas diffusion, the oxygen concentrations became even in the confined space at $720 \mathrm{~s}$. It took about $540 \mathrm{~s}$ for gases to mix evenly, showing that the nitrogen was easy to diffuse in the confined space.

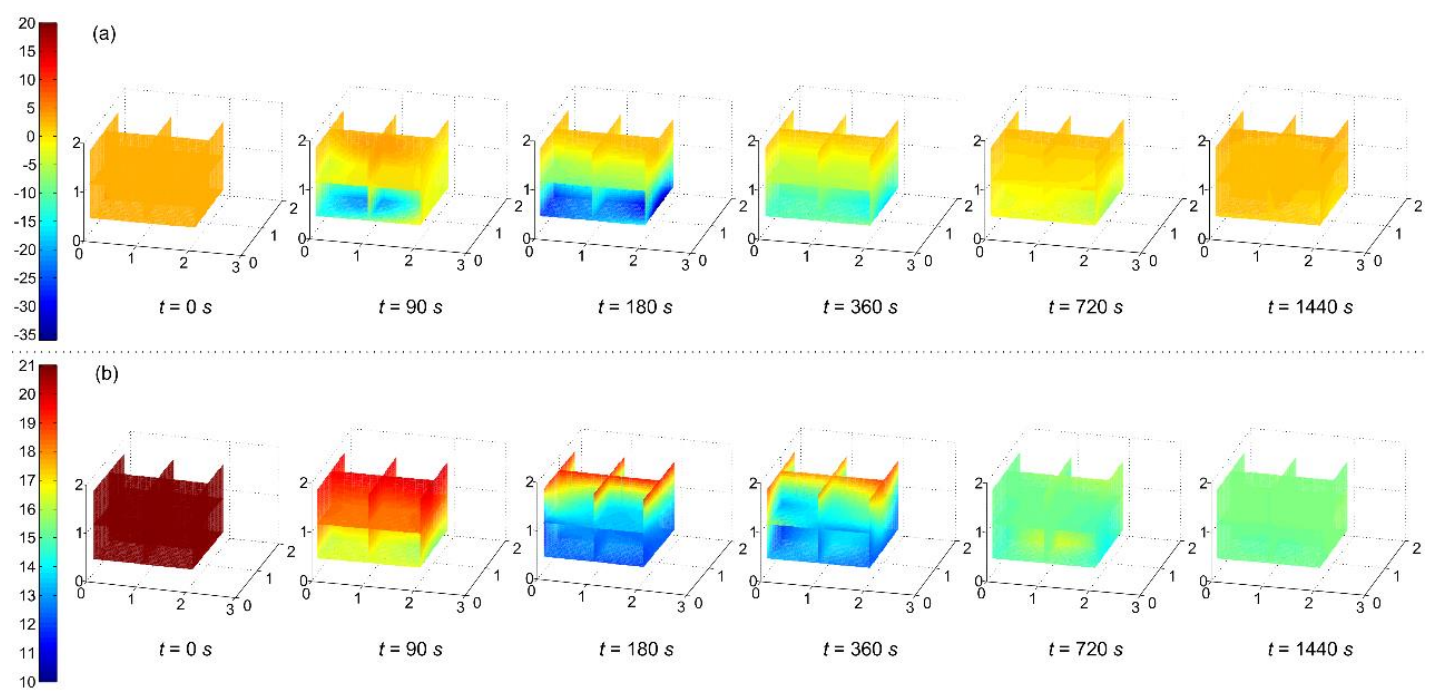

Figure 2. Temperatures (a) and oxygen concentrations (b) on six slices of $x=0.0,1.0,2.0 \mathrm{~m}, y=1.0 \mathrm{~m}$, $z=0.3,1.0 \mathrm{~m}$ at $0,90,180,360,720$, and $1440 \mathrm{~s}$.

According to the above result analysis, there were no significant differences both among the temperatures and among the oxygen concentrations in the same horizontal plane. However, changes of both the temperatures and oxygen concentrations in the vertical direction were significant. The measurement points \#13,\#14, and \#15 were arranged vertically in a line. Thus, they were selected to study the effects of different mass fluxes, injection velocities, injection port heights, and inclination angles on the heat and mass transfer in the confined space.

Figure 3 shows the plot of heat transfer capacity versus the time with different mass fluxes. When the mass flux was $0.019 \mathrm{~kg} / \mathrm{s}$, the heat transfer capacity ascends in a curve with time less than $80 \mathrm{~s}$. The increasing rate of the heat transfer capacity increased firstly, then decreased and finally remained unchanged. Because there was a temperature difference between $\mathrm{LN}_{2}$ and the low-temperature resistance steel pipe in the $\mathrm{LN}_{2}$ flowing process, $\mathrm{LN}_{2}$ absorbed the heat and vaporized. However, as the pipe temperature decreased, the vapor-liquid ratio of $\mathrm{LN}_{2}$ gradually reached a balance. The pipe inner surface temperature decreased to a certain degree after $80 \mathrm{~s}$; the gas-liquid two-phase flow was in a saturated state. There was a clear linear relationship between the heat transfer capacity and time. It could be expressed as Equation (11),

$$
Q=n+k_{\mathrm{c}} t
$$

where $k_{\mathrm{c}}$ was the cooling rate of $\mathrm{LN}_{2}$ when the $\mathrm{LN}_{2}$ was in a saturated state. In addition, in terms of each mass flux, the changes in heat transfer capacity with increasing time ( $>130 \mathrm{~s})$ followed a linear trend, showing the cooling rate could be obtained during the experiments. At the same time, the cooling rate was related to the injection condition. It represented the ability to cool down the confined space quickly. Thus, the cooling rate could be used to evaluate the cooling effect of $\mathrm{LN}_{2}$ with the combination of heat transfer. 


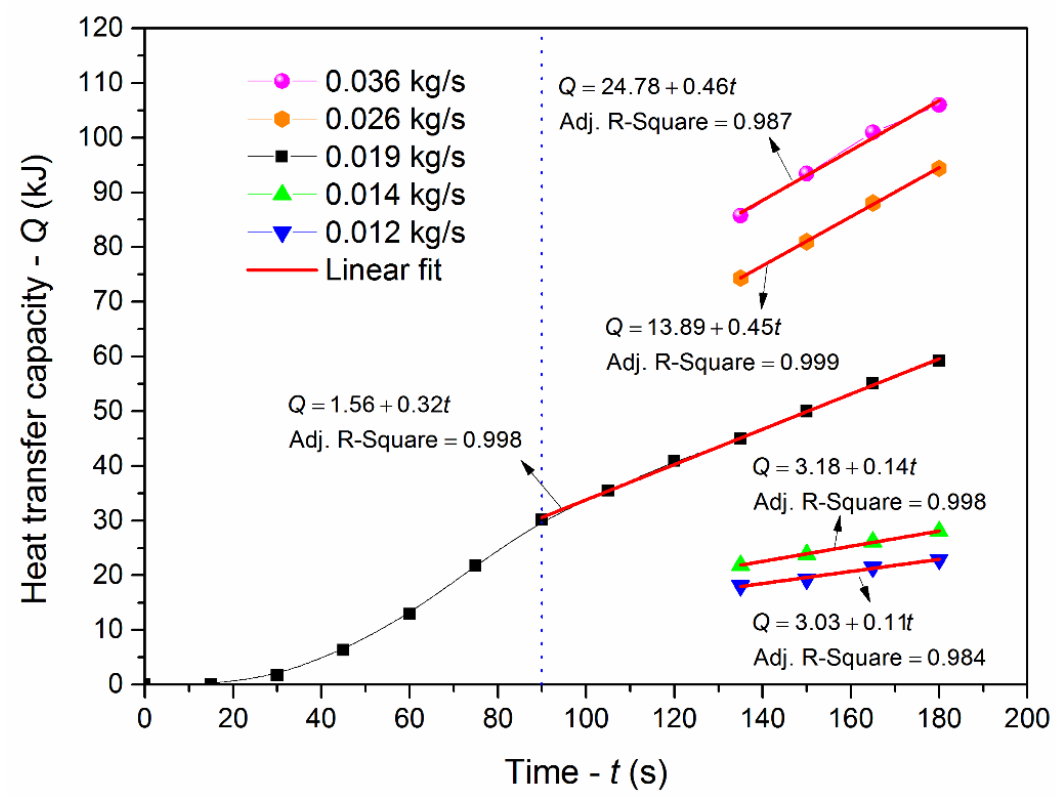

Figure 3. Heat transfer capacity versus the time of $\mathrm{LN}_{2}$ injection with different mass fluxes.

In order to verify the sealing property of the experimental confined space, the variation of the average oxygen concentrations in the confined space with increasing time ( $\geq 1140 \mathrm{~s})$ was analyzed. As shown in Figure 4, the average oxygen concentration increased slowly and linearly with time because the confined space was not completely closed. The variation rate of the average oxygen concentration was equal to the slope of a linear fitting, which was $2.91 \times 10^{-4} \% / \mathrm{s}$ and very small, indicating that the experimental confined space was of certain air tightness. It was feasible for revealing the cooling and inerting features of $\mathrm{LN}_{2}$ in confined spaces.

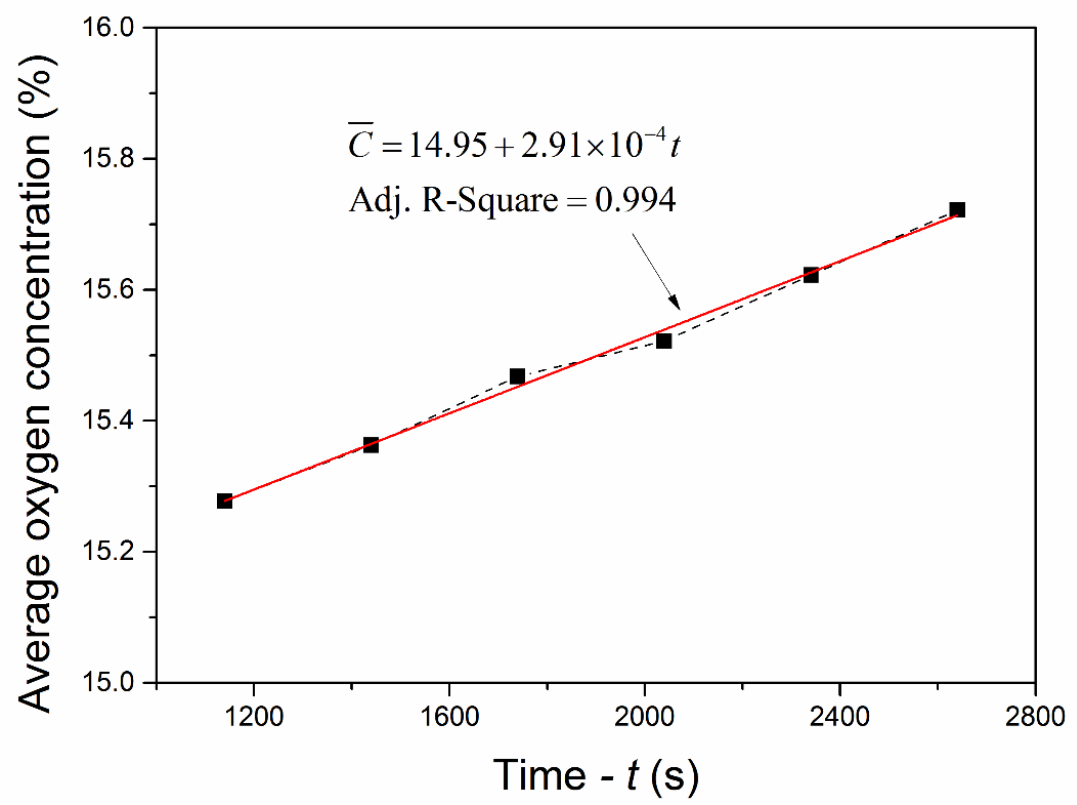

Figure 4. Average oxygen concentrations in the confined space versus time ( $\geq 1140 \mathrm{~s})$.

\subsection{Effects of Mass Flux on the Cooling and Inerting Effects}

In terms of the same injection duration of $180 \mathrm{~s}$, the variations in the temperatures and oxygen concentrations at measuring points \#13,\#14, and \#15 with increasing mass flux are shown in Figure 5. As shown in Figure 5a, the temperatures decreased with increasing mass flux. The maximum decrease 
was approximately $32{ }^{\circ} \mathrm{C}$ for \#15, which was followed by approximately $13{ }^{\circ} \mathrm{C}$ for \#14, and $2{ }^{\circ} \mathrm{C}$ for \#13. The temperatures at \#14 and \#15 decreased quickly with a mass flux increasing from 0.014 to $0.026 \mathrm{~kg} / \mathrm{s}$. The temperatures at the three points decreased slowly with increasing mass flux above $0.026 \mathrm{~kg} / \mathrm{s}$. Figure $5 \mathrm{~b}$ shows that the oxygen concentrations at the three points decreased, and began to level off with increasing mass flux above $0.026 \mathrm{~kg} / \mathrm{s}$. There was a significant decrease of approximately $6 \%$ both for \#14 and for \#15, while that for \#13 was slight. The cooling and inerting effects at \#15 became increasingly apparent with increasing mass flux, and the low-temperature low-oxygen space gradually expanded upward. For the same mass flux, the cooling effect weakened gradually with increasing height. Since the differences among the oxygen concentration at different heights in $z<1.0 \mathrm{~m}$ were very small, the inerting effect in the space was uniform.
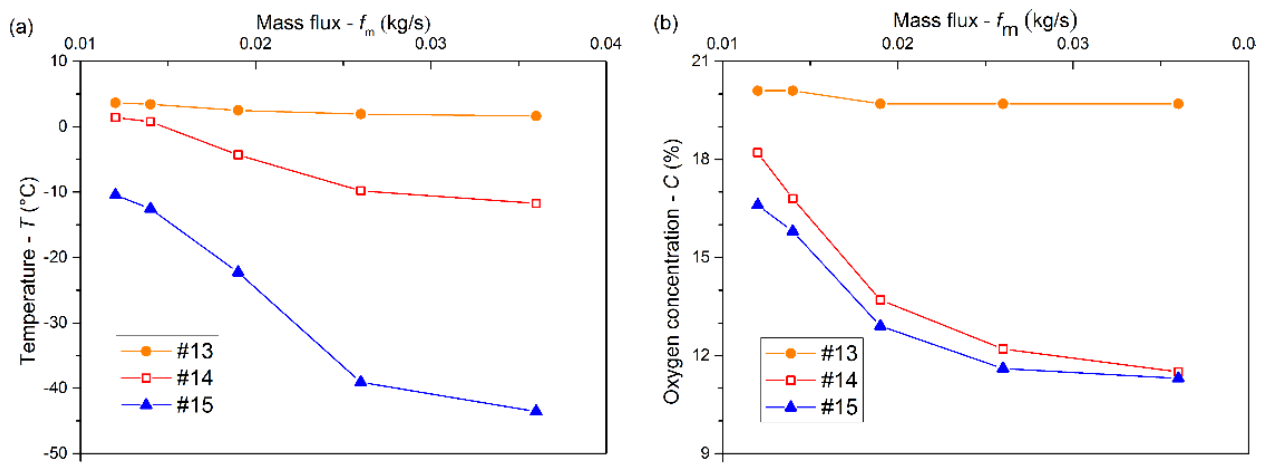

Figure 5. Temperatures (a) and oxygen concentrations (b) at measuring points \#13, \#14, and \#15 versus mass flux at $180 \mathrm{~s}$.

Figure 6a shows the changes in the cooling rate and heat transfer capacity at $180 \mathrm{~s}$ with increasing mass flux. The heat transfer capacity increased gradually with a mass flux increasing from 0.014 to $0.026 \mathrm{~kg} / \mathrm{s}$ and then began to flatten. The increasing rate of heat transfer capacity increased firstly when $f_{\mathrm{m}}<0.019 \mathrm{~kg} / \mathrm{s}$, and then decreased when $f_{\mathrm{m}} \geq 0.019 \mathrm{~kg} / \mathrm{s}$. In addition, the cooling rate had the same trend with increasing mass flux. The cooling rate began to flatten with mass flux above $0.026 \mathrm{~kg} / \mathrm{s}$. This was because that the cooling effect was certain and local (at the lower place). When $f_{\mathrm{m}}<0.019 \mathrm{~kg} / \mathrm{s}$, the mixed gas released heat easily, and the temperature decreased. When $f_{\mathrm{m}} \geq 0.019 \mathrm{~kg} / \mathrm{s}$, the temperature decreased to a specific value (approximately $-40{ }^{\circ} \mathrm{C}$ ), at which the mixed gas released heat with difficulty because of the low heat transfer efficiency. Figure $6 \mathrm{~b}$ shows the changes in the inerting coefficient at $180 \mathrm{~s}$ with mass flux. The inerting coefficient gradually decreased in a concave curve. It illustrated that the inerting effect of $\mathrm{LN}_{2}$ was gradually enhanced with a mass flux increasing from 0.014 to $0.026 \mathrm{~kg} / \mathrm{s}$ and then tended to level off, showing the decreasing enhancement extent.
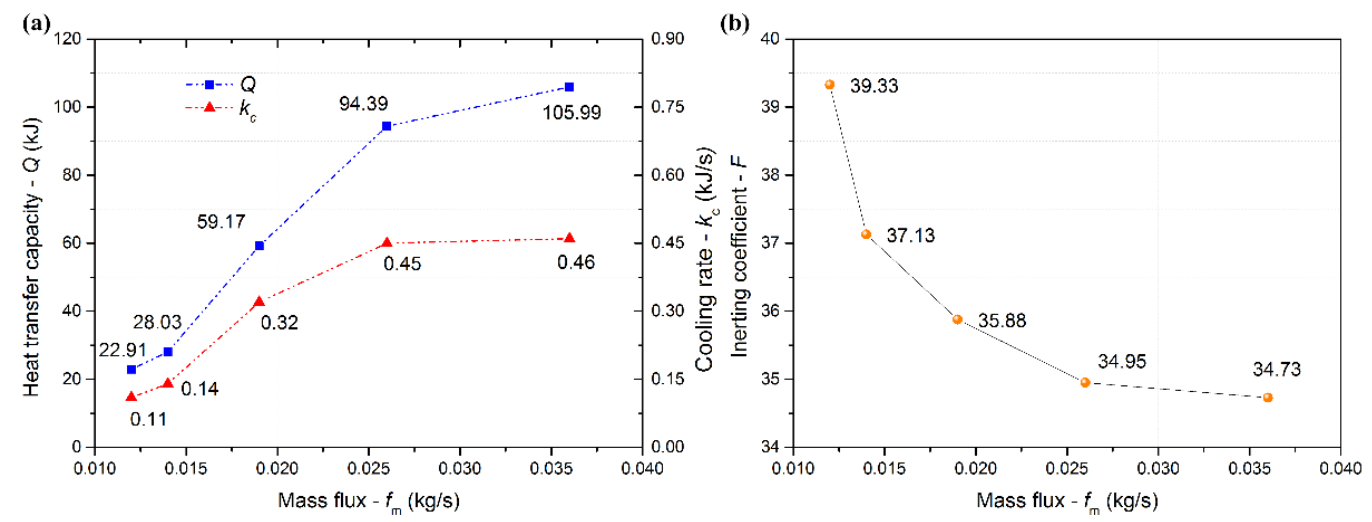

Figure 6. Cooling rate and heat transfer capacity at $180 \mathrm{~s} \mathrm{(a),} \mathrm{inerting} \mathrm{coefficient} \mathrm{at} 180 \mathrm{~s} \mathrm{(b)} \mathrm{versus} \mathrm{mass} \mathrm{flux.}$ 


\subsection{Effects of Pipe Diameter on the Cooling and Inerting Effects}

For the same injection duration of $180 \mathrm{~s}$, the changes in the temperatures and oxygen concentrations at the measurement points \#13,\#14, and \#15 with different pipe diameters are shown in Figure 7a,b, respectively. When $\Phi=4 \mathrm{~mm}$, the temperatures and oxygen concentrations at \#13, \#14, and \#15 were basically the same. The injection quantity of $\mathrm{LN}_{2}$ decreased significantly in view of a small diameter. The $\mathrm{LN}_{2}$ vaporization produced large amounts of cryogenic nitrogen gas in the steel pipe. The gas pressure gradually increased as the diameter decreased, which hindered the $\mathrm{LN}_{2}$ injection to the confined space so that the cryogenic nitrogen gas was mainly injected with only a relatively small quantity of liquid nitrogen [23]. The temperature at \#13 basically remained unchanged with a diameter increasing from 20 to $40 \mathrm{~mm}$. This was because the low-temperature area concentrated at the lower place, and there was little influence on the top in terms of heat transfer due to the small heat transfer coefficient of gas. The initial kinetic energy of the $\mathrm{LN}_{2}$ decreased with increasing diameter, which weakened the gas mixture. Thus, the oxygen concentration at \#13 increased. The temperature at \#14 increased with a pipe diameter, increasing from 12 to $40 \mathrm{~mm}$ and the minimum was $-0.2{ }^{\circ} \mathrm{C}$, but the oxygen concentration decreased with a pipe diameter increasing from 4 to $20 \mathrm{~mm}$ and then slowly increased. The temperature at $\# 15$ decreased first with a pipe diameter increasing from 4 to $20 \mathrm{~mm}$ and then increased linearly. The oxygen concentration at $\# 15$ decreased with increasing pipe diameter. According to the above result, the cooling effect at the lower place in the confined space gradually decreased with a pipe diameter increasing from 20 to $40 \mathrm{~mm}$. This could be because the increase of pipe diameter increased the contact area of $\mathrm{LN}_{2}$ with the steel pipe, increasing the amount of $\mathrm{LN}_{2}$ vaporization. In addition, the flow rate of cryogenic nitrogen gas decreased with diameter, and the mass transfer ability in the confined space weakened. Thus, the inerting effect at the lower place increased, while that at the upper place decreased.
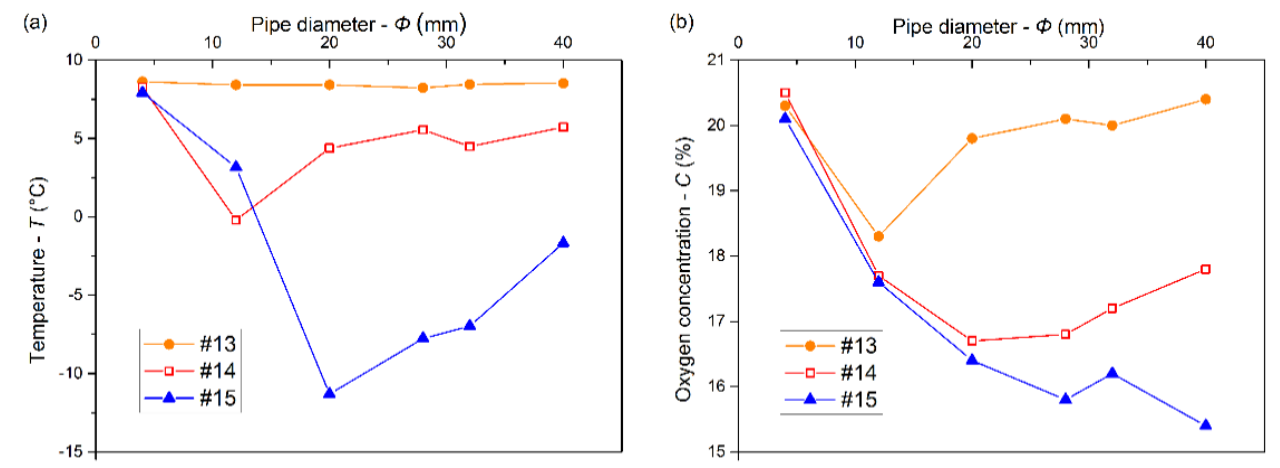

Figure 7. Temperatures (a) and oxygen concentrations (b) at measuring points \#13, \#14, and \#15 versus pipe diameter at $180 \mathrm{~s}$.

When $\Phi=4 \mathrm{~mm}, \mathrm{LN}_{2}$ vapor impeded the continuous injection of $\mathrm{LN}_{2}$ due to the small limited diameter. Thus, the heat transfer capacity in the confined space was very small, and there was also no desirable inerting effect. The plots of the heat transfer capacity at $180 \mathrm{~s}$, cooling rate, and inerting coefficient at $180 \mathrm{~s}$ versus pipe diameter increasing from 12 to $40 \mathrm{~mm}$ are shown in Figure 8 . The heat transfer capacity linearly decreased with increasing pipe diameter. The cooling rate first decreased significantly with increasing pipe diameter, and then started to level off with a pipe diameter of $28 \mathrm{~mm}$, so the cooling effect of $\mathrm{LN}_{2}$ was gradually weakened. It was because the path of $\mathrm{LN}_{2}$ flow was affected slightly by increasing pipe diameter more than $28 \mathrm{~mm}$ with a specific mass flux, resulting in the unchanged cooling effect. The inerting coefficient increased with increasing pipe diameter, illustrating that the inerting effect decreased. Hence, an appropriate diameter should be selected to improve the cooling and inerting effect in the process of $\mathrm{LN}_{2}$ injection. In this experiment, the cooling and inerting effects of $\mathrm{LN}_{2}$ was the best when $\Phi=12 \mathrm{~mm}$. 

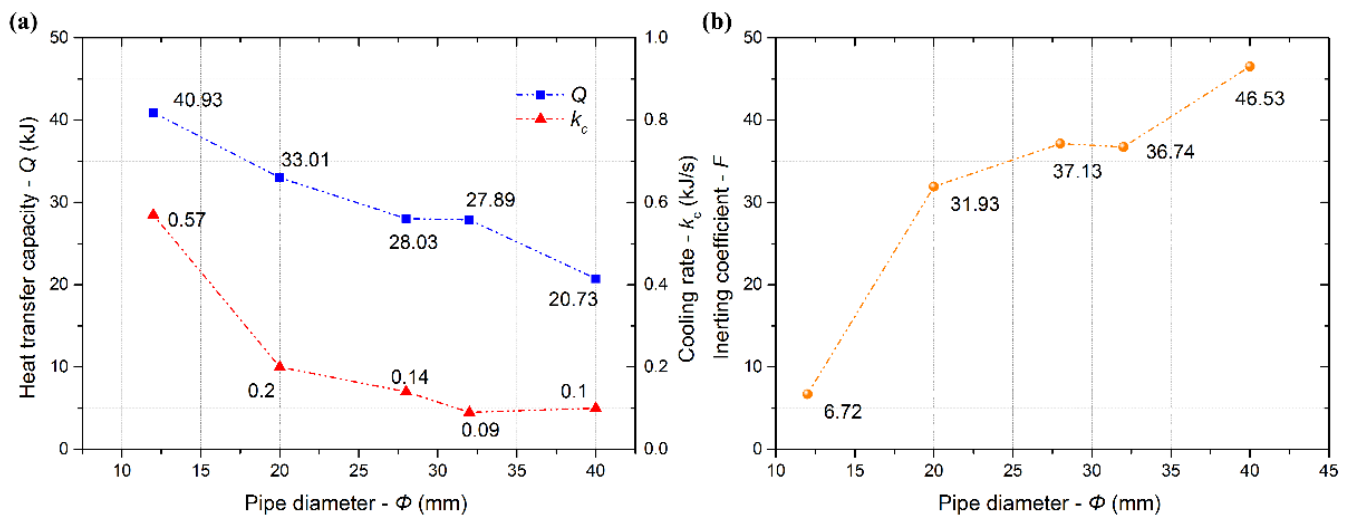

Figure 8. Cooling rate and heat transfer capacity at $180 \mathrm{~s}$ (a), inerting coefficient at $180 \mathrm{~s}(\mathbf{b})$ versus pipe diameter.

\subsection{Effects of Injection Angle on the Cooling and Inerting Effects}

In terms of the same injection duration of $180 \mathrm{~s}$, the variations in the temperatures and oxygen concentrations at the measurement points \#13,\#14, and \#15 under different inclination angles are shown in Figure 9. As shown in Figure $9 a$, the temperatures at $\# 14$ and \#15 decreased gradually with inclination angle ranging from $-30^{\circ}$ to $+30^{\circ}$, while the temperature at $\# 13$ basically remained the same. It indicated that the cooling effect in the space of $z \leq 1.0 \mathrm{~m}$ was gradually enhanced by increasing inclination angle. As shown in Figure 9b, the oxygen concentrations at \#13,\#14, and \#15 gradually converged with an inclination angle ranging from $-30^{\circ}$ to $+30^{\circ}$. The mixed effect of the gases in the confined space was improved as the inclination angle increased.
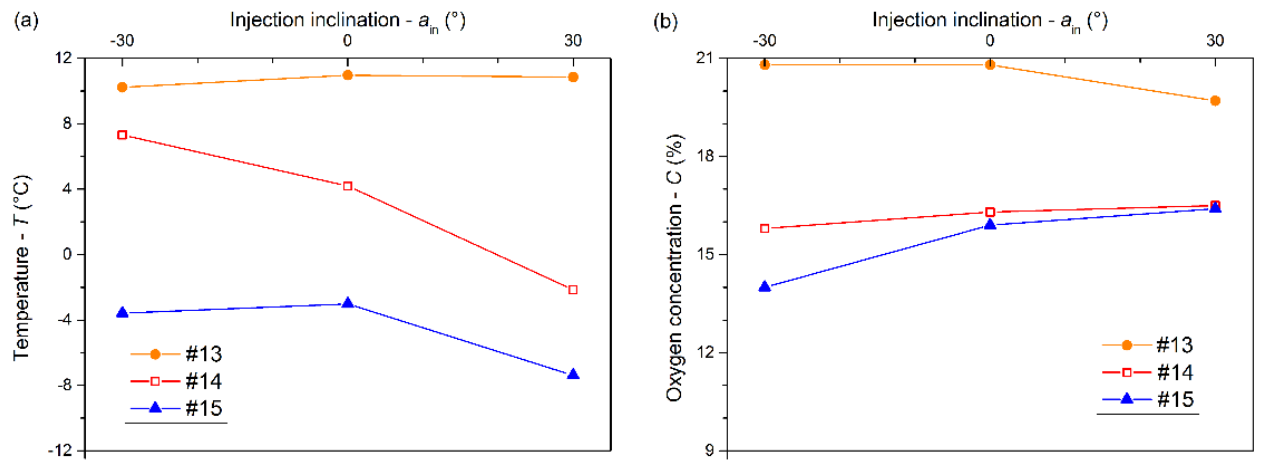

Figure 9. Temperatures (a) and oxygen concentrations (b) at measuring points \#13, \#14, and \#15 versus inclination angle at $180 \mathrm{~s}$.

The plots of the cooling rate, heat transfer capacity at $180 \mathrm{~s}$, and inerting coefficient at $180 \mathrm{~s}$ versus inclination angle are shown in Figure 10. As the inclination angle increased from $-30^{\circ}$ to $+30^{\circ}$, the heat transfer capacity increased. The $\mathrm{LN}_{2}$ of a specific mass flux mainly flowed to the lower space with $a_{\text {in }} \leq 0^{\circ}$, where the air molecule movement was slowed down. Thus, the cooling rate changed slightly when $a_{\text {in }} \leq 0^{\circ}$, which was consistent with the inerting coefficient. Dramatically, the cooling rate increased quickly when $a_{\text {in }}>0^{\circ}$. The inerting coefficient was basically unchanged when $a_{\text {in }} \leq 0^{\circ}$. However, the inerting coefficient increased with the inclination angle when $a_{\text {in }}>0^{\circ}$. It showed that the cooling and inerting effects of $\mathrm{LN}_{2}$ in confined spaces could be enhanced with the positive direction increase of inclination angle, because both the contact time and the contact area between $\mathrm{LN}_{2}$ and the air increased. 

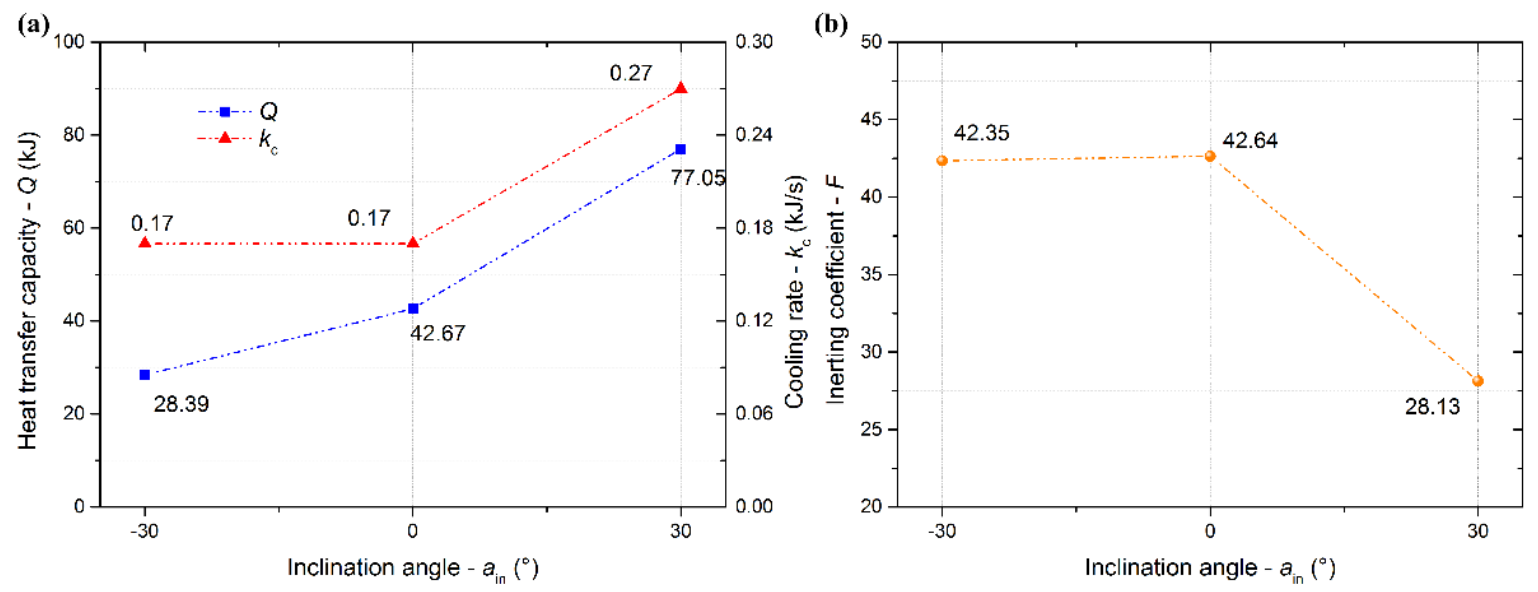

Figure 10. Cooling rate and heat transfer capacity at $180 \mathrm{~s} \mathrm{(a),} \mathrm{inerting} \mathrm{coefficient} \mathrm{at} 180 \mathrm{~s}(\mathbf{b})$ versus inclination angle.

\section{Conclusions}

In this work, the spatial distributions of both the temperatures and oxygen concentrations in the space were obtained to reveal the heat and mass transfer of $\mathrm{LN}_{2}$ under different mass fluxes, pipe diameters, and inclination angles. Additionally, a mathematical model of quantitatively evaluating the cooling and inerting effects of $\mathrm{LN}_{2}$ was proposed based on the cooling indexes (heat transfer capacity and cooling rate) and the inerting index (inerting coefficient). The results proved that the model could accurately reveal the cooling and inerting phenomenon, and it could be used for the quantitative analysis of the relationships between the injection parameters and the cooling and inerting effects of $\mathrm{LN}_{2}$ in a confined space. These studies were feasible and meaningful for getting an optimal mass flux, a pipe diameter, and an inclination angle in the site implementation to improve the cooling and inerting effects of $\mathrm{LN}_{2}$ for firefighting. The following understandings and conclusions can be drawn:

1. The low-temperature area mainly was located in the lower place owing to gravity. There was a linear relationship between the heat transfer capacity and time when $\mathrm{LN}_{2}$ reached a vaporization balance in the low-temperature resistance steel pipe. After $\mathrm{LN}_{2}$ injection, the cooling effect was only limited in the lower part of the confined space. However, there were no significant differences both among the temperatures and among the oxygen concentrations in the same horizontal plane.

2. The low-temperature low-oxygen space gradually expanded upward with increasing mass flux. The increasing pipe diameter $\left(>20 \mathrm{~mm}\right.$ ) went against the heat and mass transfer of $\mathrm{LN}_{2}$ in the confined space. Both the contact time and the contact area between $\mathrm{LN}_{2}$ and the air could increase with a positively increasing inclination angle, which strengthened the cooling and inerting.

3. The inerting effect of $\mathrm{LN}_{2}$ was gradually enhanced with a mass flux increasing from 0.014 to $0.026 \mathrm{~kg} / \mathrm{s}$ and then tended to level off. An appropriate pipe diameter should be selected to improve the cooling and inerting effects of $\mathrm{LN}_{2}$, the optimal one being $12 \mathrm{~mm}$ in this experiment. Otherwise, a positively increasing inclination angle could contribute to the cooling and inerting effects of $\mathrm{LN}_{2}$ injected into the confined space. However, there was little effect on the cooling and inerting when the inclination angle was below $0^{\circ}$.

Author Contributions: Conceptualization, H.S.; Data curation, H.J.; Formal analysis, H.J. and X.W.; Funding acquisition, H.J.; Investigation, Y.L.; Methodology, H.S.; Project administration, W.C.; Resources, W.C.; Software, H.J.; Supervision, H.S. and X.W.; Validation, Y.L. and W.C.; Visualization, X.W.; Writing—original draft, H.J.; Writing-review \& editing, H.S. 
Funding: This research was funded by the National Key Research and Development Program of China grant number [2018YFC0808100], the National Natural Science Foundation of China grant number [51604247], and the Fundamental Research Funds for the Central Universities grant number [2652017072]. And the APC was funded by the National Key Research and Development Program of China grant number [2018YFC0808100].

Acknowledgments: This study is supported by the National Key Research and Development Program of China [2018YFC0808100], the National Natural Science Foundation of China [51604247], and Fundamental Research Funds for the Central Universities [2652017072]. The authors wish to express gratitude to Prof. Bobo Shi (China University of Mining and Technology) for his critical review of this paper.

Conflicts of Interest: The authors declare no conflict of interest.

\section{References}

1. Gage, A.A.; Baust, J. Mechanisms of Tissue Injury in Cryosurgery. Cryobiology 1998, 37, 171-186. [CrossRef]

2. Knowlen, C.; Mattick, A.T.; Bruckner, A.P.; Hertzberg, A. High Efficiency Energy Conversion Systems for Liquid Nitrogen Automobiles. SAE Trans. 1998, 107, 1837-1842.

3. Proux, O.; Nassif, V.; Prat, A.; Ulrich, O.; Lahera, E.; Biquard, X.; Menthonnex, J.J.; Hazemann, J.L. Feedback system of a liquid-nitrogen-cooled double-crystal monochromator: Design and performances. J. Synchrotron Radiat. 2010, 13, 59-68. [CrossRef]

4. Ren, H. Femtosecond laser induced formation of nanostructures on silicon and silver surfaces in liquid nitrogen. Diss. Theses-Gradworks 2015. Available online: https://search.proquest.com/openview/ 16ae0ef5d4f7b71f02d4989dc63078b9/1?pq-origsite=gscholar\&cbl=18750\&diss=y (accessed on 17 April 2019).

5. Beidelman, J.A. Liquid Nitrogen Fire Extinguishing System Test Report; NASA Sti/recon Technical Report N; Argonne National Lab.: Lemont, IL, USA, 1972; Volume 77.

6. Klueg, E.P. Liquid nitrogen as a powerplant fire extinguishant. Fire Technol. 1969, 5, 197-202. [CrossRef]

7. Torikai, H.; Ishidoya, M.; Ito, A. Examination of Extinguishment Method with Liquid Nitrogen Packed in a Spherical Ice Capsule. Fire Technol. 2016, 52, 1179-1192. [CrossRef]

8. Levendis, Y.; Ergut, A.; Delichatsios, M. Cryogenic extinguishment of liquid pool fires. Process Saf. Progr. 2010, 29, 79-86. [CrossRef]

9. An, D.; Sunderland, P.B.; Lathrop, D.P. Suppression of sodium fires with liquid nitrogen. Fire Saf. J. 2013, 58, 204-207. [CrossRef]

10. Levendis, Y.A.; Delichatsios, M.A. Pool fire extinction by remotely controlled application of liquid nitrogen. Process Saf. Prog. 2011, 30, 164-167. [CrossRef]

11. Mcguire, J. Fighting building fires with liquid nitrogen: A literature survey. Fire Saf. J. 1981, 4, 15-19. [CrossRef]

12. Shi, B.; Zhou, F. Fire extinguishment behaviors of liquid fuel using liquid nitrogen jet. Process Saf. Prog. 2016, 35, 407-413. [CrossRef]

13. Tang, Y. Experimental investigation of applying $\mathrm{MgCl}_{2}$ and phosphates to synergistically inhibit the spontaneous combustion of coal. J. Energy Inst. 2018, 91, 639-645. [CrossRef]

14. Tang, Y.; Wang, H. Experimental investigation on microstructure evolution and spontaneous combustion properties of secondary oxidation of lignite. Process Saf. Environ. Prot. 2019, 124, 143-150. [CrossRef]

15. Kim, A.G. Cryogenic injection to control a coal waste bank fire. Int. J. Coal Geol. 2004, 59, 63-73. [CrossRef]

16. Mohalik, N.K.; Singh, R.V.K.; Pandey, J.; Singh, V.K. Application of nitrogen as preventive and controlling subsurface fire-Indian context. J. Sci. Ind. Res. 2005, 64, 273-280.

17. Shi, B.; Ma, L.; Dong, W.; Zhou, F. Application of a Novel Liquid Nitrogen Control Technique for Heat Stress and Fire Prevention in Underground Mines. J. Occup. Environ. Hyg. 2015, 12, D168-D177. [CrossRef] [PubMed]

18. Zhou, F.B.; Shi, B.B.; Cheng, J.W.; Ma, L.J. A New Approach to Control a Serious Mine Fire with Using Liquid Nitrogen as Extinguishing Media. Fire Technol. 2015, 51, 325-334.

19. Shi, B.; Zhou, F. Impact of heat and mass transfer during the transport of nitrogen in coal porous media on coal mine fires. Sci. World J. 2014, 2014, 4198-4205. [CrossRef]

20. Qi, S.L.; Zhang, P.; Wang, R.Z.; Xu, L.X. Flow boiling of liquid nitrogen in micro-tubes: Part II -Heat transfer characteristics and critical heat flux. Int. J. Heat Mass Transf. 2007, 50, 5017-5030. [CrossRef]

21. Reid, R.C.; Brian, P.L.T.; Weber, M.E. Heat transfer and frost formation inside a liquid nitrogen-cooled tube. Aiche J. 1966, 12, 1190-1195. [CrossRef] 
22. Shaeffer, R.; Hong, H.; Chung, J.N. An experimental study on liquid nitrogen pipe chilldown and heat transfer with pulse flows. Int. J. Heat Mass Transf. 2013, 67, 955-966. [CrossRef]

23. Wang, S.M.; Wen, J.; Li, Y.M.; Wang, S.H.; Li, Y.Z. Population balance modelling for subcooled boiling flow of liquid nitrogen in a vertical tube. Int. J. Heat Mass Transf. 2013, 60, 632-645. [CrossRef]

(C) 2019 by the authors. Licensee MDPI, Basel, Switzerland. This article is an open access article distributed under the terms and conditions of the Creative Commons Attribution (CC BY) license (http://creativecommons.org/licenses/by/4.0/). 